\title{
Drilling behaviour of Octopus mimus Gould
}

Tito Cortez ${ }^{\mathrm{a}}$, Bernardino G. Castro ${ }^{\mathrm{b}}$, Angel Guerra ${ }^{\mathrm{c}, *}$

${ }^{a}$ Universidad Arturo Prat, Avenida 11 de Septiembre, 2120 Iquique, Chile

bepartamento de Ecologia y Biologia Animal, Facultad de Ciencias, Apdo. 874, Universidad de Vigo, 36200 Vigo (Pontevedra), Spain

CInstituto de Investigaciones Marinas (CSIC), 36208 Vigo (Pontevedra), Spain

*Corresponding author: Tel: 13486 231930; fax: 13486 292762; e-mail:

brc1@iim.csic.es

\section{Abstract}

The hole-drilling behaviour of the common octopus in North Chilean waters, Octopus mimus, on nine of its molluscan prey was studied in 70 specimens of 10-2000 g body weight in the laboratory. The occurrence of perforation was low, only $24.50 \%$ of the ingested prey were drilled. The bivalve Protothaca thaca (Molina) was the prey most frequently perforated, on $73.30 \%$ of occasions. The mean length of the P. thaca ingested increased significantly with octopus weight $\left(r^{2}=0.982, p<0.001\right)$ whether or not clams had previously been drilled. The form of the holes was usually a truncated cone with an oval section. The dimensions (length and width) of the external openings of the holes were significantly dependent on octopus weight and clam length $(\mathrm{p}<0.001$ in both cases). However, the dimensions of the internal openings of the holes were only dependent on octopus size. Location of the holes differed according to the prey species. Holes made in Mytilidae shells did not have any specific position, while the apex was the area selected for drilling the gastropod Concholepas concholepas (Brugière). The most specific location occurred when Protothaca thaca was perforated; $83 \%$ of the holes were located within or close to the myostracum of the anterior, mainly, and posterior adductor muscles of the clam. Within these small areas, there was a preference for the proximal edges.

Keywords: Octopus; Cephalopods; Ecology; Feeding; Behaviour; Chile

1. Introduction 
Analysis of digestive tracts of Octopus mimus revealed this species as an important predator of the rocky shore off northern Chilean waters where it feeds on 25 different prey belonging to five zoological groups (Teleostei, Mollusca, Crustacea, Echinodermata and Polychaeta), and that, like other Octopus species, O. minus is an opportunistic predator (Cortez et al., 1995).

It is well documented that at least seven octopod species (Octopus vulgaris, O. bimaculoides, O. bimaculatus, O. micropyrsus, O. dofleini, Eledone cirrhosa and E. moschata) drill holes in amphineuran, lamellibranch, gastropod and bivalvia mollusc shells, Nautilus and crustacean carapaces (Tucker and Mapes, 1978; Nixon and Boyle, 1982; Guerra and Nixon, 1987; Saunders et al., 1991; Nixon, 1987 for a review; Nixon and Maconnachie, 1988; Mather and Nixon, 1990).

Mather and Anderson (1994) observed that Octopus dofleini have four ways of getting into a clam, and appeared, if possible, to use the easiest, resorting to drilling only when other methods were unsuccessful. McQuaid (1994) showed that drilling of bivalve Perna perna by Octopus vulgaris was dependent on bivalve size and the biggest specimens that could be opened without prior drilling were taken selectively.

The drilling activities of $\mathrm{O}$. vulgaris were shown to be carried out by a salivary papilla that lies just below the radula, which can function as an accessory radula (Nixon, 1980). The effects on shells of drilling by Octopus were studied by Nixon et al. (1980). They found that some chemical dissolution of the shell occurs during drilling, and that 'rasp marks' found on the surface of drill holes were due to the structural formation of the shell. The composition and structure of the shell itself are important in determining the size, shape and form of the cavity drilled, although the size of the octopus (O. vulgaris from the Mediterranean), which may take, $1 \mathrm{~h}$ in capturing, drilling the shell and eating the occupant, is not (Nixon and Maconnachie, 1988).

The drill-hole made by different Octopus species on bivalve shells usually has a characteristic form, which can be very useful for recognising its predatory activity on natural prey populations (Ambrose, 1986; Guerra and Nixon, 1987). 
An important part of the diet of O. mimus is based on shelled molluscs, many of them of commercial interest on the northern Chilean coast (Cortez et al., 1995). The effect of O. mimus on natural populations of these molluscs can be partially evaluated by studying the shelled remains present in its middens when they are drilled before ingestion. This information could be also of value for understanding the foraging behaviour of this species in its natural habitat, e.g. for studying prey-predator size relationships. As a preliminary step towards gathering this kind of information, a study was undertaken to investigate the drilling behaviour of O. mimus in captivity: how frequently O. mimus drills different species of molluscs, the dependence of drilling activity on the prey and octopus size, the dependence of drill-holes on octopus size and the specificity of location of drill sites in the shell of the prey.

\section{Materials and methods}

Two experiments are reported in the present paper. First, the type of response of $O$. mimus was studied by analysing the presence of drill holes in the prey ingested (mainly molluscs or hermit crabs inside empty shells). Prey species were chosen according to: (1) their importance in the natural diet of O. mimus (Cortez et al., 1995); (2) their appearance as prey in different sizes; (3) their abundance in the habitat of O. mimus; and (4) their commercial importance in the area. A summary of the prey and the size range (length of the shell) given to the octopuses are shown in Table 1.

Combinations of two or more different prey were used to feed the octopuses. However, the number of specimens of each prey was always the same and their size ranges were similar to those observed in the wild. The effect of possible behavioural modifications of the octopuses due to prey combinations was not taken into consideration. The ingestion or non-ingestion of each prey-type and the observation of prior drilling were noted. Measurements of the maximum shell length, occurrence and number of drillings were also recorded once the prey was ingested.

A second experiment was undertaken to study the relationship between the size of the octopus and the size of its prey. The influence of the prey on the number of drillings was also analyzed. Furthermore, the relationship between the size of the drillings and the size of the octopus was studied. The prey chosen was Protothaca thaca, which was 
the bivalve most frequently drilled during the first experiment. The maximum length and width of the inner and outer surfaces of the drill hole were measured using a binocular optical microscope with an eyepiece graticule $(60.05 \mathrm{~mm})$. The location of the drill sites was studied using the same prey and differentiating two areas in the surface of the shell (Fig. 1, area of impression and external area). The drillings observed in the impression area were classified into three types: (1) inner drillings, when located within the muscular impression but not in the border; (2) marginal, affecting the impression; (3) peripheral, situated outside the impression and within a radius of $0.5 \mathrm{~cm}$ surrounding the impression. Marginal and peripheral drillings were also classified by separating the impression area into four equal parts delimited by two perpendicular axes drawn from the middle of the impression and oblique to the axis of the bivalve: dorsal, posterior, ventral and anterior, as shown in Fig. 1.

Specimens of O. mimus used in both experiments were caught by diving in waters near Iquique (North of Chile). The animals were maintained in captivity in two open systems with a constant flow of sea water at temperatures ranging from 17 to $23^{\circ} \mathrm{C}$ : system $\mathrm{P}$ consisted of one pool of $100 \mathrm{~m}^{3}$ capacity with a flow of $1 \mathrm{l} \mathrm{s}^{-1}$; and system $\mathrm{T}$ was formed by eight fibre-glass tanks of $1000 \mathrm{l}$ of capacity each with a flow of $2 \mathrm{l} \mathrm{min}^{-1}$. They were fed ad libitum to allow them to adapt to the new conditions. The octopuses were classed into five weight-groups depending on their total body weight (BW) and maturity stage: 10-49 g, 50-99 g, 100-199 g, 200-499 g and 1000-2000 g. Animals belonging to the last group were mature whilst the rest were immature. On average, 30 individuals were maintained in system $\mathrm{P}$ and 40 in system $\mathrm{T}$ (5 octopuses in each tank). Octopus of similar sizes were maintained in the same tank. These specimens were not marked and thus, their individual activity could not be registered. For this reason, the results are presented by weight ranges. Both studies were undertaken between September and December 1992.

A chi-square test was used to analyse the number of drilled holes between species, valves and shell areas (Siegel and Castellan, 1988). A non-parametric test of variance was used to analyse the existence of selectivity for prey size. The shape of the drill holes (circular or ovoid) was determined by comparing the maximum length and width using a t-test (Sokal and Rohlf, 1981). Multiple regression analysis was applied to test the relationship between the size of the drill hole, the size of the bivalve and the size of 
the octopus. Linear regression analysis was used to compare the relationship between the size of the prey and the predator (Sokal and Rohlf, 1981).

\section{Results}

\subsection{Drilling by prey species}

The percentages of drillings in the shells of each species are summarised in Table 2. The number of holes drilled (single or double) and whether the hole was complete or incomplete are also indicated in Table 2.

A total of 2541 specimens of molluscs were ingested during this study. The bivalves Tagelus dombei and Lithofaga peruviana and the Polyplacophora were always ingested without being drilled. In the remaining species, individuals were drilled $24.50 \%$ of the time (21.57\% drilled once and 2.93\% twice). Shells of gastropods (mainly Tegula sp.) used as refuge by hermit crabs were also drilled by Octopus mimus.

Considering only drilled shells, the probability of double drillings was independent of the species ingested $\left(X^{2}=5.17\right.$, d.f. $\left.=2, p>0.05\right)$.

\subsection{Prey size selection}

The percentages of each prey size group of the P. thaca ingested and drilled by five groups of O. mimus are summarised in Table 3. Drilling behaviour was observed in the whole size range of octopuses (10-2000 g).

Significant differences were observed when the selectivity of prey by predators was analyzed $(\mathrm{H}=127.76$, d.f. $=4, \mathrm{p}<0.001)$. Thus, the size range of the bivalves ingested increased for heavier octopuses $\left(\mathrm{r}^{2}=0.982, \mathrm{p}<0.001\right)$. The frequency of drilling observed in bivalves of similar size ranges decreased when the size of the octopus increased. On the other hand, octopuses of similar sizes increased the frequency of drilling with larger bivalves. Therefore, the frequency of drilling decreased when the ratio octopus size to bivalve size increased. 
The data presented in Table 3 and their corresponding averages in Fig. 2 show that bigger octopuses tend to select larger sizes of bivalves, whether the shell was drilled or not. Furthermore, for all the octopus weight-groups except that between 200-499 g, the average size of the bivalves ingested after being drilled was higher than for those ingested without drilling. These differences are not, however, significant.

\subsection{Clam and octopus size and hole dimensions}

Octopuses ranging from 10 to $2000 \mathrm{~g}$ drilled holes of between 0.5 and $2.5 \mathrm{~mm}$ in length and from 0.5 to $2.3 \mathrm{~mm}$ in width in Protothaca thaca. The shapes of the drilled holes were mainly ovoid, on both the inner and outer surfaces ( $\mathrm{p}<0.05$ and $\mathrm{p}<0.001$, respectively). Therefore, the shape is an incomplete cone with an ovoid or circular section.

The weight of the octopus and the size of the bivalve determined the external dimensions (length and width) of the hole (multiple determination coefficient $r^{2}=0.941$ and $\mathrm{r}^{2}=0.911$, respectively, both $\mathrm{p}<0.001$ ). Both variables increased with the weight of the octopus ( $p<0.001)$ and the size of the bivalve $(\mathrm{p}<0.001)$. However, the weight of the octopus alone determined the internal dimensions of the hole $\left(r^{2}=0.771\right.$ and $r^{2}=$ 0.720 for internal length and weight, respectively, both $\mathrm{p}<0.001$ ) increasing with the weight of the octopus. Within the same weight-group of octopuses, the maximum and minimum external length of the hole increased significantly with the size of bivalves ( $p$ $<0.001$ and $\mathrm{p}<0.01$, respectively).

\subsection{Location of the drills}

The drilled holes in mytilids (Perumytilus purpuratus, Acanthopleura ater and Semimytilus algosus) were randomly distributed, but in the gastropod Concholepas concholepas they were always located near the apex.

The situations of 573 drill holes made by 70 specimens of Octopus mimus in 535 specimens of Protothaca thaca are shown in Fig. 3. There was no preference for either right or left valves ( $p>0.05)$. The majority of the holes (91\%) were in the vicinity of the impressions of the adductor muscles (anterior and posterior) in both valves. The 
percentage of complete holes in these areas was high (96\%) while only $15 \%$ of holes in the rest of the valve were complete. The anterior impression was drilled more frequently than the posterior one (Table 4, $\mathrm{p}<0.0001$ ).

Drillings observed close to the muscular impressions (Fig. 3 and Table 4) were more abundant in the border of the adductor muscles than in the inner part ( $<<0.0001)$. The number of holes in the insertion of the anterior adductor muscle was significantly higher in its posterior border than in the anterior one $(\mathrm{p}<0.001)$. In contrast, the number of holes in the insertion of the posterior adductor muscle was significantly higher in its anterior border than in its posterior one $(\mathrm{p}<0.001)$. This concentration of drillings in these areas is higher than would be expected if they were randomly distributed all over the insertions (Fig. 3).

\section{Discussion}

Within the eight orders in the class Cephalopoda, the order Octopoda is unique in including bivalve and gastropod molluscs on its diet (Nixon, 1987). Shells can be opened by traction on the valves or by injecting salivary substances (after drilling through the valve) to relax the adductor muscles and weaken the union between valves (Nixon and Maconnachie, 1988). Studies with specimens of Octopus vulgaris revealed that this species can ingest the mytilid Perna perna after using different strategies depending on the size of the prey. Small P. perna were opened by traction of the valves whilst specimens of bigger sizes were drilled. Specimens of medium sizes were ingested after using either strategy (McQuaid, 1994). This strategy is interpreted by McQuaid as conforming to the predictions of optimal foraging theory (Hughes, 1980), which predicts as optimal feeding behaviour that which produces the maximum energy yield per unit of time. Bigger prey produce more energy but the time and energy required to open the shell is higher and could be energetically unviable for the predator. This seems to happen with big bivalves that could be opened by traction. However, the high energetic requirements of this strategy make the octopus drill the shell and, although it is a slower process, the energy used is lower. Therefore, for equal availability of prey sizes, the octopus will choose the largest prey it is able to open by traction. This was the case of Octopus vulgaris fed with Perna perna. Observations in the present study seems to point in the same direction because the size of Protothaca thaca ingested increased 
with the weight of the octopus and the frequency of drilling increased as the ratio of octopus weight to bivalve size decreased.

The weight of the Octopus mimus was correlated with the dimensions of the drill holes in Protothaca thaca. This result differs from the results for Octopus vulgaris in which the size of the hole was not related to the size of the predator (Nixon and Maconnachie, 1988). The discrepancy between these results could be related to the species studied or, more probably, to differences in the size range used (10-2000 g in the present study and 150-310 g in the O. vulgaris experiment). The buccal structures of O. mimus involved in the process of drilling are unknown. However, due to similarities in dimensions of the holes and anatomical similarities between both octopus species (Cortez, 1995) the structures are probably the same as observed for O. vulgaris (Nixon, 1979, 1980). The size of these structures probably increases with the size of the octopus as noted for other buccal structures and the radula (Nixon, 1973). Therefore, bigger octopuses produce bigger holes. However, if the changes in these structures is not as obvious as those observed for the body weight of the octopus, the dimensions of the holes produced by animals of different sizes would only be distinguished if the sizes of the specimens were very different.

The size of the bivalve influenced the dimensions of the drilled hole. This result is probably a mechanical consequence of the drilling process, made from the outer to the inner part of the valve, and also depends on the shape of the structures that produce the hole. The hole is an incomplete cone narrowing towards the inner surface of the shell. The external hole is wider when the valve is thicker. However, the dimensions of the hole in the inner surface of the valve depend on the size of the octopus, and, therefore, on the size of the anatomical structures that made the hole. The shape of the drill, the location of the holes and the relationship between this variable and the size of the octopus is useful for understanding the trophic ecology and predatory behaviour of this species.

O. mimus preying on Protothaca thaca choose the nearest area to the myostracum of the adductor muscles, mainly the posterior border of the anterior muscle. Choosing the area of the myostracum is also common in the drilling behaviour of Octopus vulgaris preying upon lamellibranches (for review, see Nixon and Maconnachie, 1988). However, in the 
case of $\mathrm{O}$. vulgaris no preference was observed for drilling mainly the anterior adductor muscles or any specific areas of the myostracum. The precision with which the area drilled was chosen (percentage errors observed for O. mimus were low, see Table 4) raises questions of why the octopus choose that area and how they locate it. The answer to the first question should explain, at least in the case of O. mimus, not only the selection of the myostracum but also particular areas of it. A possible hypothesis for $\mathrm{O}$. vulgaris is that the drilling would allow the release in situ of the octopus saliva containing substances that would weaken the union between the adductor muscle and the shell (Nixon and Maconnachie, 1988). Analysing the bivalves immediately after being opened by drilling and before being ingested would test this hypothesis. The location of the drill site, preferentially in the posterior marginal zone of the adductor muscle, must depend on some other effects of the saliva other than its debilitating action on the adductor muscle. One of these effects could be a direct action on the nervous system that controls muscular contraction and relaxation. This control is undertaken by means of diffusion of saliva up to the spinal-cerebrum ganglion situated near the adductor muscle. This process would correspond to that described for the saliva of $O$. vulgaris (Nixon and Maconnachie, 1988).

To date, nobody has investigated the question of how the octopus locate the suitable area for drilling. May be this is because no other species is so specific in its choice of drill site as O. mimus is when preying on Protothaca thaca. Further studies should be carried out to answer this question. To date, the evidence presented for O. vulgaris implies that, in spite of their highly developed nervous system and elaborate behaviour, these animals are unable to differentiate some basic characteristics of the objects they handle, such as shape, weight or size (Wells, 1978). Recognition of these characteristics should be a necessity if an octopus is to make drill holes so specifically located as those made by $\mathrm{O}$. mimus in the shell of Protothaca thaca. The importance of the chemo-tactile sense, which is very well developed in Octopus, for locating the drill hole should also be tested.

\section{Acknowledgements}

We thank Mr. F. Casas and Mrs. M.T. Fernandez for their invaluable technical assistance and A.F. Gonzalez and F. Rocha, members of the Vigo Cephalopod 
Ecophysiology Group, for their comments and suggestions. We also wish to express our thanks to the SCUBA divers J. Corrotea, C. Gaete and W. Cotton for their help in the sample collection. This work was made possible with the financial support of SEPLAC from the 1st Region de Chile (to T. Cortez).

References

Ambrose, R.F., 1986. Effects of octopus predation on motile invertebrates in a rocky subtidal community. Marine Ecology Progress Series 30, 261-273.

Cortez, T., Castro, B.G., Guerra, A., 1995. Feeding dynamics of O. mimus (Mollusca: Cephalopoda) in northern Chile waters. Marine Biology 123, 497-503.

Cortez, T. 1995. Biologia y ecologia del pulpo comun Octopus mimus Gould, 1852 (Mollusca: Cephalopoda) en las aguas litorales del norte de Chile. Ph.D. Thesis, Universidad de Vigo, Spain.

Guerra, A., Nixon, M., 1987. Crab and mollusc shell drilling by Octopus vulgaris (Mollusca: Cephalopoda) in the Ria de Vigo (north-west Spain). Journal of Zoology 211, 515-523.

Hughes, R.N., 1980. Optimal foraging theory in the marine context. Oceanography and Marine Biology: An Annual Review 18, 423-481.

Mather, J.A., Anderson, R.C., 1994. Octopuses and clams: The packaging problem. In: Abstracts of The Behaviour and Natural History of Cephalopods, CIAC 94, Vico Equense, Napoli, Italy, p. 21.

Mather, J.A., Nixon, M., 1990. Octopus vulgaris drills Chiton. Journal of Cephalopod Biology 1 (2), 113-116.

McQuaid, C.D., 1994. Feeding behaviour and selection of bivalve prey by Octopus vulgaris Cuvier. Journal of Experimental Marine Biology and Ecology 177, 187202.

Nixon, M., 1973. Beak and radula growth in Octopus vulgaris. Journal of Zoology 170, 451-462.

Nixon, M., 1979. Has Octopus vulgaris a second radula?. Journal of Zoology 187, 291296.

Nixon, M., 1980. The salivary papilla of Octopus as an accessory radula for drilling shells. Journal of Zoology 190, 53-57. 
Nixon, M., 1987. Cephalopod diets. In: Boyle, P.R. (Ed.), Cephalopod Life Cycles, Vol.

2, Comparative Reviews. Academic Press, London, pp. 201-219.

Nixon, M., Boyle, P.R., 1982. Hole-drilling in crustaceans by Eledone cirrhosa

(Mollusca: Cephalopoda). Journal of Zoology 196, 439-444.

Nixon, M., Maconnachie, E., 1988. Drilling by Octopus vulgaris (Mollusca:

Cephalopoda) in the Mediterranean. Journal of Zoology 216, 687-716.

Nixon, M., Maconnachie, E., Howell, P.G.T., 1980. The effects on shells of drilling by Octopus. Journal of Zoology 191, 75-88.

Saunders, W.B., Knight, R.L., Bond, P.N., 1991. Octopus predation on Nautilus:

Evidence from Papua New Guinea. Bulletin of Marine Science 49 (1-2), 280-287.

Siegel, S., Castellan, N.J., 1988. Nonparametric Statistics for the Behavioral Sciences, McGraw-Hill, New York.

Sokal, R., Rohlf, F., 1981. Biometry. The Principles and Practice of Statistics in Biological Research, 2nd. ed., W.F. Freeman, San Francisco.

Tucker, J.K., Mapes, R.H., 1978. Possible predation on Nautilus pompilius. Veliger 21, 95-98.

Wells, M.J., 1978. Octopus. Physiology and Behaviour of an Advanced Invertebrate, Chapman and Hall, London. 
Table 1

Summary of species and size of prey fed to Octopus mimus

\begin{tabular}{ll}
\hline Prey & Size range (mm) \\
\hline Polyplacophora & $10-80$ \\
Chiton granosus (Frembly) & $10-80$ \\
Acanthopleura echinata (Barnes) & \\
Bivalvia & $10-90$ \\
Protothaca thaca (Molina) & $10-50$ \\
Perumytilus purpuratus (Lamarck) & $10-50$ \\
Aulacomya ater (Molina) & $10-50$ \\
Semimytilus algosus (Gould) & $20-100$ \\
Lithophaga peruviana (Orbigny) & $20-100$ \\
Tagelus dombeii (Lamarck) & \\
Gastropoda & $10-50$ \\
Concholepas concholepas (Brugière) & \\
\hline
\end{tabular}

Table 2

Number of individuals ingested (N) by Octopus mimus and frequency (\%) of drilling per species

\begin{tabular}{llllll}
\hline Species & $\mathrm{N}$ & $\mathrm{P}$ & $\mathrm{PP}$ & $\mathrm{PPC}$ & PPI \\
\hline Polyplacophora & 30 & 0.0 & - & - & - \\
Protothaca thaca & 730 & 68.0 & 5.3 & 16.0 & 84.0 \\
Mytilidae & 54 & 53.7 & 17.2 & 40.0 & 60.0 \\
Lithophaga peruviana & 1286 & 0.0 & - & - & - \\
Tagelus dombeii & 74 & 0.0 & - & - & - \\
Concholepas concholepas & 15 & 26.6 & 0.0 & - & - \\
Gastropoda (Tegula sp.) with Paguridae & 352 & 15.1 & 7.5 & 75.0 & 25.0
\end{tabular}

Data pooled for 70 octopuses of 10-2000 g body weight. P: \% of shells with one hole; PP: \% of shells with 2 holes; PPC: \% of shells with two complete holes; PPI: \% of shells with 2 holes and one of them, at least, incomplete. Mytilidae comprises the following species: Perumytilus purpuratus, Aulacomya ater and Semimytilus algosus. 
Percentage of Protothaca thaca of different length-groups ingested by five weightgroups of Octopus mimus

\begin{tabular}{lllllll}
\hline Octopus size (g) & $\mathrm{N}$ & \multicolumn{7}{l}{ Clam size $(\mathrm{mm})$} & & \\
\cline { 3 - 7 } & & $10-19$ & $20-29$ & $30-39$ & $40-49$ & $50-59$ \\
\hline $10-49$ & 48 & $29(71)$ & $63(80)$ & $8(100)$ & $0(-)$ & $0(-)$ \\
$50-99$ & 208 & $8(100)$ & $75(78)$ & $16(100)$ & $1(100)$ & $0(-)$ \\
$100-199$ & 229 & $9(50)$ & $69(58)$ & $16(80)$ & $5(80)$ & $1(100)$ \\
$200-499$ & 161 & $4(71)$ & $56(63)$ & $27(84)$ & $7(73)$ & $6(33)$ \\
$1000-2000$ & 83 & $1(100)$ & $27(52)$ & $38(68)$ & $24(90)$ & $10(92)$ \\
\hline
\end{tabular}

$\mathrm{N}$ : total number of clams ingested by each octopus size-group. Number in brackets shows the percentage of clams ingested after being drilled.

Table 4

Location of the drill-holes made by Octopus mimus in Protothaca thaca, both valves pooled

\begin{tabular}{lll}
\hline Location of perforation & Anterior impression & Posterior impression \\
\hline Impressional & 305 & 218 \\
Internal & 117 & 58 \\
Marginal & 160 & 101 \\
Dorsal & 32 & 33 \\
Posterior & 85 & 3 \\
Ventral & 21 & 7 \\
Anterior & 22 & 58 \\
Peripheral & 28 & 59 \\
Dorsal & 3 & 28 \\
Posterior & 3 & 8 \\
Ventral & 6 & 0 \\
Anterior & 16 & 23 \\
External & & 20 \\
\hline
\end{tabular}

Fig. 1. Nomenclature of the different areas of the shell of Protohaca thaca where the drill-holes were located: ia: impression area, d: dorsal, p: posterior, v: ventral, a: 
anterior; ib: impression margin; mi: muscular impression; pa: peripheral area; ea: external area.

Fig. 2. Relationships between mean Octopus mimus weight (OW) and mean size of clam (CS) ingested. Data are plotted separately for drilled (filled circles) and undrilled (open circles) clams.

Fig. 3. Location of drill-holes made by Octopus mimus in the shell of Protothaca thaca. Open and filled circles represent complete and incomplete holes, respectively. 